\title{
The First Russian Project of the Asian Academy: New Geopolitical Vector \\ Olga Fedotova
}

\author{
Doctor of Pedagogical Sciences; Professor; Head of Department of Education and Pedagogical Sciences,
} Southern Federal University, Rostov on Don, Russia

Email: fod06@mail.ru

\section{Vladimir Latun}

PHD in Geography; Docent; Institute of Earth Sciences, Southern Federal University, Rostov on Don, Russia

Email: vlatun@yandex.ru

\section{Doi:10.5901/mjss.2015.v6n4p356}

\section{Abstract}

The purpose of this paper is the proof of the fact that the desire to create new political alliances and economic associations, including European and Asian countries, is not a manifestation of the latest trends in Russia's development strategy. In the beginning of the 19th century research projects about future geopolitical forms of the world including Russia's place in the new coordinate system, reflecting the views of individual government officials are being developed. The "Project of the Asian Academy" designed in 1810 by famous Russian statesman Earl Sergei Semenovich Uvarov, which is hardly known even in Russia, is detailed analyzed. The article shows that it is possible to distinguish two large clusters in this project: training of staff, with the ability to explore and to translate the unique artifacts of Asian culture and research in various scientific fields represented in Asia. The importance is given to the study of the history of Asia, in particular, the history of the Mohammedan Dynasties in Asia with the application of the general picture Islamism to it. New thematic fields of research are: Geography of Asia, religious ideas of Asia, oriental Philology and Philosophy. This indicates the aim to recreate a complete picture of Asian culture and introduce it to Europeans in 19th century.

Keywords: Russia, development strategy, Asian culture, Sergei Uvarov, Asian Academy, project, education of Europeans, research of Asia

\section{Introduction}

In modern geocultural situation globalization trends are parallel with the trend to fragmentation of the modern world. Political, economic, socio-cultural and ethno-confessional diversity of European and Asian countries, continuing in the $\mathrm{XXI}$ century, is an important source of instability in the world. Despite the fact that the technical opportunities are increasing between civilizations, there are no clearly observed trends to the removal of cultural and mental disagreements between the inhabitants of the West and the East in modern conditions. They appear most clearly on the boundaries of civilizations within the Eurasian frontier.

Russia seeks to recognize and take into account in its policy features of cultural universals and features of the local cultural identity, developing in modern Eurasian space (Fedotova, 2013). However, the desire to create new political alliances and economic associations, including European and Asian countries, is not a manifestation of the latest trends in Russia's development strategy. As a Eurasian country with complex ethnosocial structure, with more than 180 peoples and ethnic communities living on its territory, Russia has long been interested in cultural and scientific problems in Europe and Asia.

The beginning of the XIX century in Russia was a period of radical governmental transformations. The increase of the Russian territory by one-third in both the European and the Asian parts that took place in the XVIII century led to an interest in planning the future (Mark, 2012). The first decades of the XIX century in Russia were marked by a surge of interest to the problems of the world order and identity of the country in the geo-cultural area of Europe and Asia. Being, along with Turkey, one of the few countries which fully apply the term "Eurasian country", Russian comprehended its political and socio-cultural relations with the countries of the Eurasian continent. In the beginning of the century research projects, reflecting the views of individual government officials about future geopolitical forms of the world and Russia's place in the new coordinate system, are being developed. 


\section{Historical Context}

Project of the Asian Academy ("Projet d'une Academie Asiatique"), hardly known even in Russia, is of particular interest, this project was designed in 1810 by famous Russian statesman Earl Sergei Semenovich Uvarov (1786-1855). Earl Sergei Uvarov held many public positions in Russia, including the Minister of Public Education that was in the period from 1833 to 1849. In 1832, he formulated the famous triad, reflecting the Russian imperial ideology of the time "Autocracy, Orthodoxy and Nationality", which later became the basis of the "theory of official nationality". Grammatical construction used by Uvarov mirrored syntactic paradigm of the French Revolution motto, "Liberty, Equality, Fraternity." This amplified the effect of the perception by contemporaries of Uvarov's imperial triad. He wanted to rally the country around his triad, unite for the good of Russia, of its power and enlightenment. The discovery of the Cape of Good Hope, giving the way to the Indian Ocean, changed according to Uvarov, the structure of the political world and acquainted Europe with new natural spaces and cultural artifacts of the Eastern countries. As the European maps of the XIX century show, Asia was significantly superior to Europe in surface area and had considerable climatic diversity (Fig 1, 2).

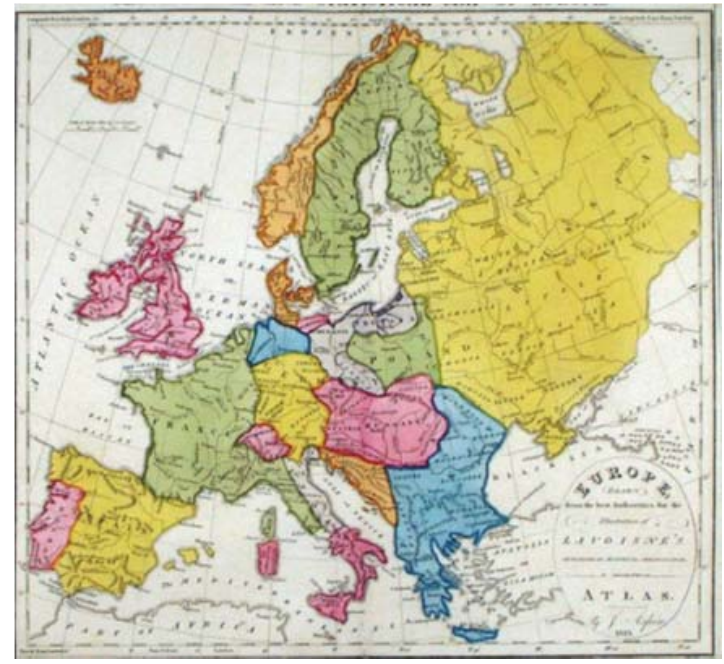

Figure 1. Map of Europe (Geographical and Statistical Map of Europe, 1810)

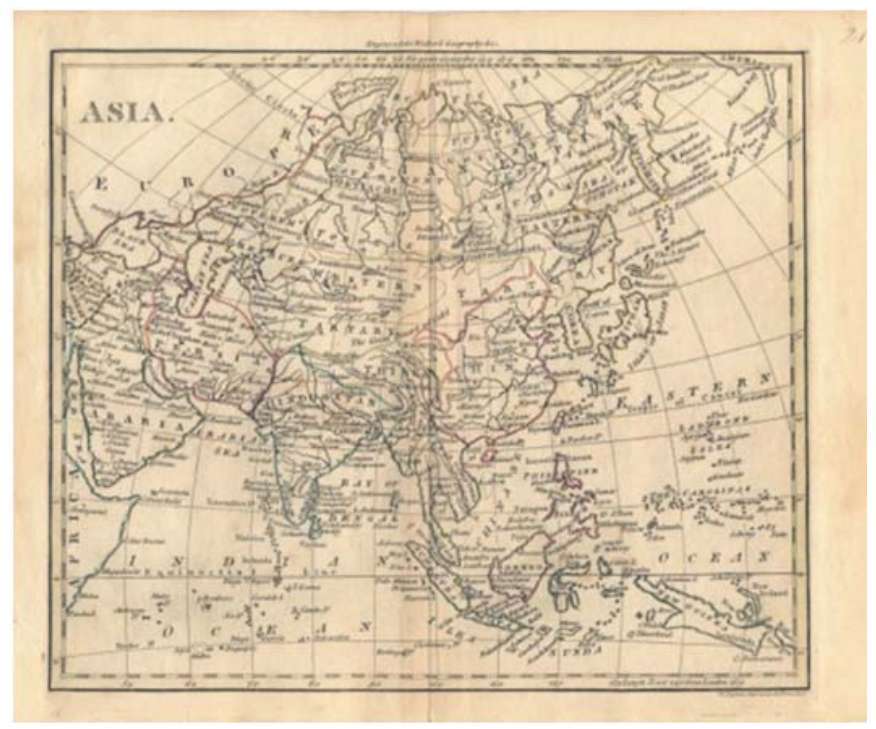

Figure 2. Map of Asia (Map "Asia" 1810)

European part of Russia formed a large share of the entire continent (Fedotova, Latun, Okuneva, 2014). North of Asia 
belonged to Russia totally. Despite the presence of a discussion of the question about where the border between Europe and Asia lies, researchers note the uniqueness of the material, spiritual and political culture of Europe and Asia of the 19th century (Knothe, 2010; Ercilasun, 2010; Morrison, 2014), the interest of European scientists of 18 - 19th centuries to Asian countries (Kruetzmann, 2007).

Given the above, the aim of this study is to identify the qualitative uniqueness of research content on "The Asian Academy project" by Uvarov, which is the first attempt to recognize the huge cultural potential of Asian countries and their comparison with the countries of Europe in the Russian scientific discourse.

\section{Materials and Methods}

The study is based on the hypothesis that the text of "The Asian Academy project" reflects worldviews of Russian statesmen, whose cultural priorities were initially focused on the study of the culture of Europe with the lack of information about the culture and traditions of Asian countries. Clarification of the conceptual approach of the creator of the first project of systematic study of Asian culture by Uvarov will help to determine what the essence of Russia's first "Asian turn" in the history of the humanities is.

\subsection{Source base research}

The object of study is Russian translation of "The Asian Academy Project" made by Uvarov. At the same time we take into account the fact that in its original version "The Asian Academy Project" by Uvarov, whose Russian was poor, was written in French (Ouwaroff S., 1810). After its publication it has been translated into German (Uvarov, 1811) and then into Russian Uvarov, 1811) and became the property of the European and Russian scientific thought. Russian version of the project was published in the first and second issues of the magazine "Herald of Europe" in 1811.

\subsection{Instruments}

To implement the hypotheses of the study such theoretical methods are used: interpretation, comparative method, analysis, synthesis, generalization. Among special methods, the method of content analysis is used (Cohen, Manion \& Morrison, 2007). Semantic categories of content analysis are the concepts of "Europe" and "Asia".

Units of account at different stages of the research in the context of concrete tasks are the names of continents, countries, religions, personalities whose names are used by Uvarov in the context of the characteristics of culture, philosophy, science of European and Asian countries. The results of the content analysis are represented by simple bargraphs (Davis, 1974; Freeman, Walters \& Cambel, 2008).

\section{Results and Discussion}

Being a European thinker, Uvarov first proves that is not the West but the East is the cradle of enlightenment: "Asia is the focus in that enlightenment expired, spilling all over the earth circle: this beautiful hypothesis, surprisingly corresponding sacred tradition, should be incontrovertibly honored" [12]. In order to confirm or refute this author's statement, we will carry out a content analytical study of the text of "The Asian Academy Project" taking as units of account mentioning of geographical names related to the European and Asian continents (Fig. 3.).

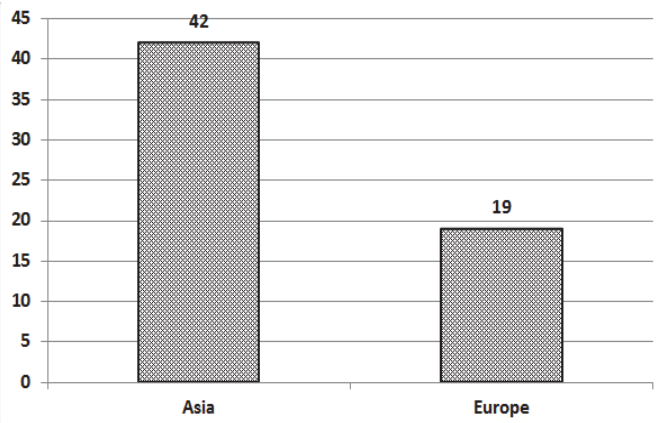

Figure 3. Range of distribution of geographical names mentioned in "The Asian Academy Project" 
As shown by the geographical names ratio, Asia as a new, untapped continent is the focus of Uvarov attention.

Uvarov shows in definite examples that the ancient Greeks were looking for enlightenment in India, borrowing basics of philosophies and concepts of morality. He argues that the philosophy of number was known much earlier by China and India, rather than Pythagoras. The project pays great attention to such distinctive countries like China and India. It is noteworthy that Europe represented by Russia, and Asia in the face of China and India appear in the Uvarov's project as large countries with subordinate territories, with unique cultural characteristics (Fig. 4).

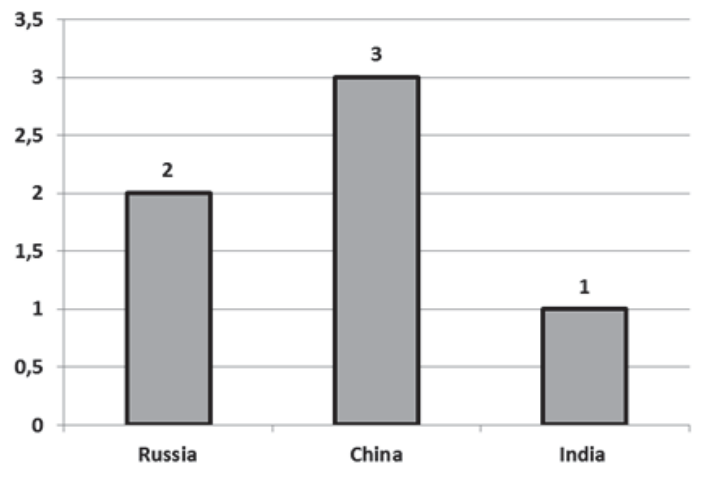

Figure 4. Distributions' polygon of dependent territories in the countries mentioned in "The Asian Academy Project"

Russia is presented by its Asian territories - Siberia and Georgia, which became part of Russia in 1801. China is presented by its territories such as Manchuria, Tibet and Mongolia. Each of them, according to Uvarov, is important for research because it keeps its originality: the language and traditional way of life. India is seen as a country, which includes such a historical region as Bengal.

Europe and Asia are constantly compared for such items as religion and personalities, being the glory of their continents (Fig 5).

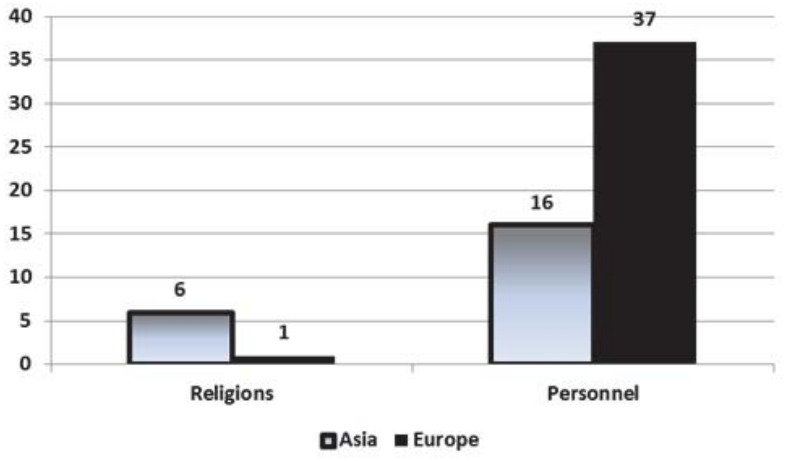

Figure 5. The ratio of religions and personalities in "The Asian Academy Project"

As it can be seen from the histogram, Asia presents a multi-religious part of the world, while Europe is represented as a region professing only Christianity. The ratio of mentioned personalities shows that Uvarov was familiar with the works of science and culture of Europe. However, the author of the project makes logical and meaningful emphasis on the fact that the ideas of a small cohort of Asian philosophers, mathematicians and poets have been creatively interpreted by Europeans and then deployed in their system of scientific knowledge without reference to the pioneers of these ideas. Assessing the geographical position of Russia, Uvarov states that it "approved by its base in Asia", has long land borders connecting it with many peoples of the East. However, he notes that the research interests of Russian scientists are limited by the territory of the Russian Siberia, although it has the closest contacts with Turkey, China, Persia and Georgia.

Uvarov outlines two main activities of the established Asian Academy. With some degree of conditionality there can be distinguished two large clusters - 1) training of staff, with the ability to explore the unique artifacts of Asian culture and 2) research in various scientific fields represented in Asia.

1) One of the activities of the Asian Academy is to ensure the preparation of Russian interpreters, which would 
allow European researchers to get acquainted with the treasures of literature, history and philosophy in their native European languages. Content of their professional activities, as suggested by Uvarov, will be the translation and analysis of philosophical, literary and religious works of eastern authors. This, in his opinion, would be of great service to European philosophy, literature and theology, where new scientific direction could develop of an interdisciplinary nature - Archaeology of metaphysics. European literature could be enriched through the translations of eastern poetry, in particular with Chinese poetry that Europeans were not yet familiar with.

2) Areas of research, as stated in the project of the Asian Academy should include several main lines. The importance is given to the study of the history of Asia, in particular, the history of the Mohammedan Dynasties in Asia with the application of the general picture Islamism to it. Also a detailed study of Jewish history, determined the development of European civilization, is important. According to Uvarov, only Asia can explain the history of the migration of peoples, without understanding of the causes and mechanisms of which Europe can not have a solid foundation of its existence.

A significant direction of activity of the Russian Academy of Asia should be the study of statistics, astronomy and geography of the East. When studying the geography of the East, Uvarov recommends paying attention to the "geography of Asia in general" and "Mohammedan geography", which use the Arabic translation of the book of the famous geographer and traveler Ibn-Haukal. Uvarov gives great importance for studying biblical geography.

The "sphere of philology" is in a special unit to identify - Jewish, Indian and Chinese literature, diverse groups of Asian languages, philology (divided into etymology, grammar and criticism). Philosophical and religious writings, according to Uvarov, must become the most important research direction, allowing Europeans to penetrate deeply into methyl structures of Eastern peoples, to understand their cultural characteristics.

Considering the specific research topics, Uvarov makes an attempt to identify desideratum, which include translations of the Vedas, the composition of Sanskrit grammar and vocabulary of the Sanskrit, translation of the ancient Indian epic "Mahabharata" (The Mahābhārata) and Oriental poetry into European languages. This indicates the aim to recreate a complete picture of Asian culture and introduce it to Europeans.

\section{Conclusion}

Russia is a Eurasian country that is most closely connected with the traditions of both Europe and Asia. In the beginning of the XIX century Russian statesmen sought to make their country a kind of geopolitical and cultural integrator. Having an idea of how science should be organized in the numerous academies in European countries, the Russian government officials paid attention to the need to establish a research center for the study of the culture of Asian countries.

A special feature in Minister of Education Uvarov approach is his conviction that, despite the scientific and technological progress, neither Europe nor Asia is the cradle of culture and education. He points directly to the fact that the intellectual and cultural heritage of Asia was used by European thinkers without reference to the true primary sources and authors of many ideas. However, he does not remove the charges from Russian scientists who have not explored the north of Asia, which belonged only to Russia. It is regrettable that this project was not implemented in time.

In Uvarov's thoughts on the necessity of "the Asian turn" in science and research of political, geographical, statistical and philosophical problems of Asia one can see the definite conjugation with the realities of the present. In addition to political and economic alliances with the countries of the Asian continent, Russian science is currently conducting a study of various problems of development in Asia, creating special research institutions and cooperating with researchers from Asian countries.

\section{Acknowledgements}

The article is written thanks to support of Southern Federal University (Russian Federation) (Grant № 213.01-072014/15ПЧВГ "Threats to national security in the context of geopolitical competition and models of aggressive and hostile behavior of young people").

\section{References}

Cohen L., Manion L. \& Morrison K., (2007). Research methods in education. London and New-York: Routledge, 638 p. Davis P., (1974). Data description and representation. Oxford: Oxford University Press, 120 p.

Ercilasun, K., (2010). On the relations between state and religion in Asia (16-19th centuries). Journal of Asian History. 44 (70-78). 
Fedotova O., Latun V., Okuneva I., (2014). Visual Image of the Continent in Russian Textbooks on Geography (1825-2013). Procedia Social and Behavioral Sciences. 141 (731-737).

Fedotova, O., (2013). The Content of a Site of the President of Russia as the Information Indicator of Realization of Counter-Terrorism Strategy in Russia. Middle-East Journal of Scientific Research. 16 (392-396).

Freeman J., Walters S., Cambel M., (2008). How to display data. Oxford: Leckwell Publishing, 109 p.

Geographical and Statistical Map of Europe. Map engraved by J. Walker. Set with statistical data. (1810). http://www.pastpages. co.uk/site-files/Page05-Maps-Europe.htm

Knothe, F., (2010). East meets west: Cross-cultural influences in glassmaking in the 18th and 19th centuries. Journal of Glass Studies. $52(201-216+273-274)$.

Kruetzmann, H. (2007). Geographical research in Chinese Central Asia: Aims and ambitions of international explorers in the 19th and $20^{\text {th }}$ centuries. Erde. 138 (369-384).

Map "Asia" 1810 - copper plate print. Cartograph: Walkers's Geography \& Co Publisher http://store.mapsofworld.com/antique_maps/ continent-and-region-maps-1-2-3-4-5/asia/1810-asia

Mark, R.A., (2012). Mit Schwert und Feder: Russland und die Eroberung Mittelasiens seit Peter | [With sword and pen: Russia and the conquest of Central Asia since Peter]. Osteuropa. 62 (79-104).

Morrison, A. (2014). Camels and colonial armies: The logistics of warfare in central Asia in the early 19th century. Journal of Economic and Social History of Orient. 57 (443-485).

Ouwaroff S., (1810). Project d'une Academie Asiatique. St. Peterburg: Gedrueckt bei A.Pluchart et Comp., 50 p.

Uvarov S., (1811). Ideen zu einer asiatishen Academie. St.Peterburg: Gedrueckt bei A. Pluchart et Comp., 66 p.

Uvarov S., (1811). The Asian Academy Project. Herald of Europe, 1:3-50. http://az.lib.ru/z/zhukowskij w a/text 1811 